\title{
Assessment of patients' warfarin knowledge and anticoagulation control at a joint physician- and pharmacist-managed clinic in China
}

This article was published in the following Dove Press journal:

Patient Preference and Adherence

\author{
Xingang $\mathrm{Li}^{1,2}$ \\ Shusen Sun ${ }^{3}$ \\ Qiaoyu Wang' \\ Buxing Chen ${ }^{4}$ \\ Zhigang Zhao ${ }^{1,2}$ \\ Xiaowei $\mathrm{Xu}^{4}$ \\ 'Department of Pharmacy, Beijing \\ Tiantan Hospital, Capital Medical \\ University, Beijing, People's Republic \\ of China; ${ }^{2}$ Precision Medicine \\ Research Center for Neurological \\ Disorders, Beijing Tiantan Hospital, \\ Capital Medical University, Beijing, \\ People's Republic of China; ${ }^{3}$ College \\ of Pharmacy and Health Sciences, \\ Western New England University, \\ Springfield, MA, USA; ${ }^{4}$ Department of \\ Cardiology, Beijing Tiantan Hospital, \\ Capital Medical University, Beijing, \\ People's Republic of China
}

Purpose: Warfarin is a widely used anticoagulant with a narrow therapeutic index, and it requires close monitoring and adequate patient education. We aimed to assess the knowledge level regarding warfarin therapy among its users and to identify the factors that significantly influence anticoagulation control.

Patients and methods: Patients attending the Warfarin Clinic at the Beijing Tiantan Hospital were enrolled in this study. Patients' knowledge on warfarin was assessed using a validated Anticoagulation Knowledge Assessment (AKA) questionnaire. Patients' responses to each question were analyzed to identify areas of improvement in current warfarin education. International normalized ratio (INR) control was defined by the time in therapeutic range (TTR) calculated using the Rosendaal method. Spearman correlation analysis was used to investigate the association between TTR and the independent variables.

Results: A total of 65 patients were enrolled in this study. Eleven questions were answered correctly by $<50 \%$ of the patients. A total of 858 INR results were recorded; 432 INR values $(50.3 \%)$ reached the predefined goals, and the mean TTR was $49.8 \% \pm 24.8 \%$. There were significant associations between TTR and patients' AKA scores $(R=0.356, P=0.004)$ and between TTR and patients' educational levels $(R=0.339, P=0.006)$. No significant association was observed between other factors (age and duration of anticoagulation) and TTR. The INR outcome measure was positively associated with patients' knowledge on warfarin and their educational levels.

Conclusion: Areas for improvement in patient education have been identified, and processes for educational modification are currently in development.

Keywords: International normalized ratio, educational level, People's Republic of China

\section{Plain language summary}

We aimed to identify the factors that significantly influence anticoagulation control. Patients' knowledge on warfarin was assessed using a validated Anticoagulation Knowledge Assessment (AKA) questionnaire, and analysis of the AKA responses was used to identify the areas for improvement in patient education. We found that the INR outcome measure "time in therapeutic range" is positively associated with patients' warfarin knowledge and educational levels among the patients of our clinic, and pharmacists should spend more time to educate patients with low levels of education and warfarin knowledge.

\section{Introduction}

Warfarin remains widely used by patients with cardiovascular and/or cerebrovascular diseases in mainland China. ${ }^{1,2}$ Due to high interindividual variability, the anticoagulant activity of warfarin has to be monitored using the international normalized ratio 
(INR) to ensure that an adequate yet safe dose is taken. ${ }^{3-5}$ The therapeutic and adverse effects of warfarin depend largely on the percentage of time during which the INR is within the therapeutic range. ${ }^{6}$ Anticoagulation clinics can help patients to manage their warfarin therapy and to achieve better clinical outcomes. ${ }^{7}$

To effectively manage patients on warfarin therapy, an anticoagulation clinic jointly managed by a physician and a pharmacist has been established at the Beijing Tiantan Hospital since May 2013. The role of the pharmacist is to provide patients with individualized anticoagulant education, management, and follow-up to ensure that their INR values are within the therapeutic goals. However, in our practice, we found that some patients' INR values were always suboptimal, with large variations. It has been shown that patients' knowledge of warfarin can improve anticoagulation control, with a decrease in adverse drug reaction and other associated complications. ${ }^{8}$ To date, there have been no studies that have either assessed the knowledge level among warfarin users in mainland China or examined the relationship between patients' warfarin knowledge and anticoagulant control. There is an urgent need to identify the factors related to patients' INR variations through assessment of patients' warfarin knowledge.

\section{Aims of the study}

The aims of this study were 1) to assess the knowledge level of patients receiving warfarin therapy in an anticoagulant clinic by using the validated Anticoagulation Knowledge Assessment (AKA) questionnaire and 2) to examine the relationship between patients' warfarin knowledge and anticoagulant control as measured by the INR.

\section{Methods}

\section{Study setting}

Beijing Tiantan Hospital is a 1,150-bed tertiary-care, teaching institution. The anticoagulation clinic accepts all patients requiring warfarin therapy discharged from the hospital. Prior to the initiation of warfarin therapy, each patient is educated by the clinic's pharmacist about warfarin therapy, the session generally lasting about 30 minutes on average. The content of the verbal education includes the following: 1) warfarin therapy (treatment rationale, benefits, and length); 2) medication administration (dosing, when to take a dose, how to store the medication, and what to do in case of a missed dose); 3) drug-drug or drug-food interactions; 4) activity or procedure precautions (fall, contact sports, shaving or brushing, surgery, or dental procedures); 5) dietary considerations and consistency; 6) side effects (signs of overanticoagulation or disease recurrence, and what to do in case of bleeding); 7) when to contact clinicians; and 8) laboratory monitoring (INR and frequency). Written education materials are also provided to each patient, including a list of warfarin-interacting medications or foods. For illiterate patients, drawings are used to highlight the main teaching points during verbal education. Patients are asked to read the written information carefully at home and contact the clinic's pharmacist if they have any questions following the reading of the written material. This study was approved by the institution review board of Beijing Tiantan Hospital, Capital Medical University, Beijing, PRC. Written informed consent was obtained from patients after the nature and purpose of the study were explained.

\section{Study population and the questionnaire}

The study population was composed of patients undergoing warfarin therapy who visited the clinic from September 2015 to June 2017. Inclusion criteria were as follows: 1) patient had received a verbal anticoagulation education and received written educational material before participating in the study; 2) patient had taken warfarin continuously for $>3$ months to ensure that warfarin had reached the steady state; and 3) patients were able to visit the clinic for each of the 1-month follow-ups and had at least five INR measurements during the 1-year study period.

The AKA questionnaire was selected to assess patients' warfarin knowledge. ${ }^{8-10}$ The AKA questionnaire comprises 29 multiple-choice questions related to different aspects of warfarin therapy. The English questionnaire was translated into a Chinese version according to the standard translation procedures. ${ }^{11}$ The following information was obtained from patients' medical records: gender, age, educational level, duration of therapy, and diagnosis. Patients who met the inclusion criteria were invited to the study, and those who consented to the study self-completed the questionnaire at the clinic.

\section{INR monitoring}

Patients were required to visit the clinic at regular intervals (every month), and their INR values were measured during each visit. INR testing was performed using a Roche CoaguChek XS handheld coagulation analyzer or ACL9000 coagulation analyzer (Instrumentation Laboratory). ${ }^{12}$ The two methods were prevalidated to ensure that the INR results were comparable. The target range of INR was 2.5-3.5 for heart valve replacement and 2.0-3.0 for other indications, according to the hospital anticoagulation protocol. INR control, the 
secondary study outcome, was defined by both the number of INR values within the therapeutic range as well as the time in therapeutic range (TTR), calculated using the Rosendaal method. ${ }^{13}$ This method adds each patient's TTR and divides it by the total times of observations. In addition to recording the results in terms of each INR value, patients' adverse reactions to warfarin were also recorded.

\section{Data extraction and statistical analysis}

The level of anticoagulation knowledge was determined based on the total score on the AKA questionnaire and the number of questions answered correctly. Each question was graded and was given one point for a correct answer or zero for a wrong answer. To avoid grading errors, each questionnaire was graded by two study investigators. Patients who answered at least 21 questions correctly $(72.4 \%$ correct $)$ were considered to have obtained a passing score, as suggested in a previous study using the AKA questionnaire. ${ }^{10}$

Statistical analyses were conducted using SPSS (version 19.0; IBM Corporation, Armonk, NY, USA). Continuous variables were expressed as mean $\pm \mathrm{SD}$, and categorical data were presented as numbers and percentages. Spearman correlation analysis was used to investigate the association between TTR and the independent variables (gender, age, duration of warfarin therapy, education level, and AKA questionnaire score). Significance was defined as $P$-value $<0.05$.

\section{Results}

\section{Baseline characteristics}

Totally, 125 patients met the inclusion criteria and were invited for the study; 71 patients consented, and 70 completed the questionnaire ( $98.6 \%$ completion rate). A total of 65 valid questionnaires were included for the final analysis (four patients failed to come to the clinic for follow-ups, and one patient had less-than-five INR measurements). The demographic and clinical data of the patients are presented in Table 1.

The mean age of the patients was $67.4 \pm 13.0$ years, and the sample included 35 female patients $(53.8 \%)$. Nine patients (13.8\%) had only completed primary school education, a total of 6 years' schooling. The majority of patients were being treated for atrial fibrillation $(n=44,67.7 \%)$. Other indications included pulmonary embolism $(n=9,13.8 \%)$ and valve replacement $(n=5,7.7 \%)$. Indication categories are not mutually exclusive, and patients with multiple indications were included in all applicable categories. Most patients had been treated for at least 1 year, except that two patients $(3.1 \%)$
Table I Baseline characteristics of patients who completed the questionnaire $(\mathrm{N}=65)$

\begin{tabular}{|c|c|}
\hline Parameters & n (\%) \\
\hline \multicolumn{2}{|l|}{ Age $($ mean $=67.4$ years; $S D=\mid 3.0$ years $)$} \\
\hline$\leq 59$ years & $8(12.3)$ \\
\hline 60-79 years & $50(76.9)$ \\
\hline$\geq 80$ years & $7(10.8)$ \\
\hline \multicolumn{2}{|l|}{ Gender } \\
\hline Male & $30(46.2)$ \\
\hline Female & $35(53.8)$ \\
\hline \multicolumn{2}{|l|}{ INR goal } \\
\hline $2.0-3.0$ & $60(92.3)$ \\
\hline $2.5-3.5$ & $5(7.7)$ \\
\hline \multicolumn{2}{|l|}{ Indication } \\
\hline Atrial fibrillation & $44(67.7)$ \\
\hline Atrial fibrillation and cardioembolic stroke & $2(3.1)$ \\
\hline Atrial fibrillation and myocardial infarction & $2(3.1)$ \\
\hline Atrial fibrillation and pulmonary embolism & $\mathrm{I}(\mathrm{I} .5)$ \\
\hline Pulmonary embolism & $9(13.8)$ \\
\hline Heart valve replacement & $5(7.7)$ \\
\hline Cardioembolic stroke & $\mathrm{I}(\mathrm{I} .5)$ \\
\hline Dilated cardiomyopathy & $\mathrm{I}(\mathrm{l} .5)$ \\
\hline \multicolumn{2}{|c|}{ Clinical events that occurred during the study } \\
\hline Bleeding & $2(3.1)$ \\
\hline Thromboembolism & $\mathrm{I}(\mathrm{l} .5)$ \\
\hline \multicolumn{2}{|l|}{ Duration of warfarin therapy } \\
\hline$<2$ years & I $8(27.7)$ \\
\hline $2-4$ years & $32(49.2)$ \\
\hline$>4$ years & $15(23.1)$ \\
\hline \multicolumn{2}{|l|}{ Education } \\
\hline Primary school & $9(13.8)$ \\
\hline Junior middle school & I5 (23.I) \\
\hline Senior middle school & $24(36.9)$ \\
\hline College & $17(26.2)$ \\
\hline \multicolumn{2}{|l|}{ AKA score $($ mean $=\mid 5.6, S D=3.8)$} \\
\hline$\leq 10$ & $6(9.2)$ \\
\hline $11-15$ & $22(33.8)$ \\
\hline $16-20$ & 3 I (47.7) \\
\hline$\geq 21$ & $6(9.2)$ \\
\hline \multicolumn{2}{|l|}{ TTR $($ mean $=49.8 \%, S D=24.8 \%)$} \\
\hline$\leq 25$ & $17(26.2)$ \\
\hline $26-50$ & $17(26.2)$ \\
\hline $5 \mathrm{I}-75$ & $20(30.8)$ \\
\hline$\geq 76$ & II (I6.9) \\
\hline
\end{tabular}

Abbreviations: INR, international normalized ratio; AKA, Anticoagulation Knowledge Assessment questionnaire; TTR, time in therapeutic range.

were treated for $<1$ year. For the assessment of individual INR goal values preset by the clinic, 60 patients $(92.3 \%)$ had a goal range of $2-3$, and five patients $(7.7 \%)$ with heart valve replacement had a goal range of 2.5-3.5. A total of 858 INR values were recorded, 432 INR values $(50.3 \%)$ reached the predefined goals, and the mean TTR was $49.8 \% \pm 24.8 \%$. Among the 65 patients, two patients had minor bleeding and one patient experienced a thromboembolic event during the study period. 


\section{Analysis of answers to the questionnaire}

Of the 65 patients, only $9.2 \%(n=6)$ achieved a passing score or were able to answer at least 21 questions correctly on the 29-item AKA questionnaire, and none of the patients were able to score $100 \%$. The mean AKA questionnaire score was 15.6 \pm 3.8 , with the being range $5-23$ points. Patients scored the highest on Question 8 (what to do when patient runs out of warfarin) and Question 14 (the best time to take warfarin), with scores of $96.9 \%$ and $89.2 \%$, respectively. Out of the 29 questions, 11 questions were answered correctly by $<50 \%$ of the patients (Table 2).

\section{Association analysis}

No significant association was found between age or the duration of warfarin therapy on the one hand and the TTR on the other (Table 3). As shown in Table 3 and Figure 1,

Table 2 Percentages of correct responses to the 29 questions in the AKA questionnaire

\begin{tabular}{|c|c|c|}
\hline Number & Question (correct answers are underlined) & $\begin{array}{l}\text { Answered } \\
\text { correctly }\end{array}$ \\
\hline I & $\begin{array}{l}\text { Which one of these medications is recommended if you are taking Coumadin (warfarin) and want relief from a headache? } \\
\text { a. Advil } \\
\text { b. Motrin } \\
\text { c. Aspirin } \\
\text { d. Tylenol }\end{array}$ & $10.8 \%$ \\
\hline 2 & $\begin{array}{l}\text { Which of the following food items would interfere with your Coumadin (warfarin) medication? } \\
\text { a. Bacon } \\
\text { b. Broccoli } \\
\text { c. Bananas } \\
\text { d. Peeled cucumbers }\end{array}$ & $67.7 \%$ \\
\hline 3 & $\begin{array}{l}\text { While on Coumadin (warfarin) medication, in which of the following would you go directly to the emergency room? } \\
\text { a. Small bruises } \\
\text { b. Your appetite dramatically increases } \\
\text { c. Nosebleed which will not stop bleeding } \\
\text { d. Gums which bleed for a few seconds after brushing teeth }\end{array}$ & $76.9 \%$ \\
\hline 4 & $\begin{array}{l}\text { You just remembered that you forgot to take your evening Coumadin (warfarin) medication dose last night. You would- } \\
\text { a. Skip the dose of Coumadin (warfarin) you missed } \\
\text { b. Take the missed Coumadin (warfarin) dose right now } \\
\text { c. Wait and take two doses of Coumadin (warfarin) this evening } \\
\text { d. Take one-half of the missed dose of Coumadin (warfarin) right now }\end{array}$ & $60.0 \%$ \\
\hline 5 & $\begin{array}{l}\text { While on Coumadin (warfarin) you- } \\
\text { a. Should not eat spinach } \\
\text { b. Can eat spinach one time a month } \\
\text { c. Can eat as much spinach as you would like whenever you would like } \\
\text { d. Can eat spinach but need to eat the same amount regularly every week }\end{array}$ & $52.3 \%$ \\
\hline 6 & $\begin{array}{l}\text { While out with friends for dinner, you have just finished your third glass of wine. This amount of alcohol consumed in a } \\
\text { single evening will- } \\
\text { a. Cause a decrease in your INR } \\
\text { b. Cause an increase in your INR } \\
\text { c. Not affect you or your Coumadin (warfarin) dose in any way } \\
\text { d. Make you sick when taking Coumadin (warfarin) medication }\end{array}$ & $24.6 \%$ \\
\hline 7 & $\begin{array}{l}\text { While in your pharmacy, you notice multivitamins are on sale. After some thought, you decide that you may need a } \\
\text { multivitamin tablet. You would- } \\
\text { a. Purchase the multivitamin and begin taking it regularly } \\
\text { b. Not take a multivitamin formulation because it will cause a blood clot while taking Coumadin (warfarin) } \\
\text { c. Start taking it and bring the multivitamin to your next Coumadin Clinic visit to show the pharmacist } \\
\text { d. Purchase the multivitamin but not start taking it until you talked with the pharmacist at your Coumadin Clinic }\end{array}$ & $44.6 \%$ \\
\hline 8 & $\begin{array}{l}\text { If you ran out of your prescription for your Coumadin (warfarin) you would- } \\
\text { a. Borrow Coumadin (warfarin) from a friend, as long as it is the same dose as yours } \\
\text { b. Call and ask for refills for that day so you do not miss a dose of Coumadin (warfarin) } \\
\text { c. Wait until your next appointment that is just a few days away to get a new prescription } \\
\text { d. Do nothing because you have taken Coumadin (warfarin) long enough; otherwise, there would be more refills on your } \\
\text { prescription }\end{array}$ & $96.9 \%$ \\
\hline
\end{tabular}


Table 2 (Continued)

Number Question (correct answers are underlined)

$9 \quad$ Which of the following is an effect of Coumadin (warfarin) medication that will most likely be experienced?

a. Stroke

b. Leg clot

c. Bruising

d. Blood in the urine

10 You have a cold, which includes a runny nose and cough. You-

a. Could safely take Nyquil to help get rid of the runny nose and cough

b. Take your friend's medication that he/she uses for a bad cold because he/she is also on Coumadin (warfarin) medication

c. Would call the Coumadin Clinic and tell the pharmacist you are on Coumadin (warfarin) medication and ask what you can take for your cold

d. Decide it is safer to suffer through the cold because most cold medications will interact with your Coumadin (warfarin) medication

II When making a dental appointment while taking Coumadin (warfarin) medication, you need to remember you-

a. Cannot have procedures done on your teeth while taking Coumadin (warfarin)

b. Must tell your dentist you are taking Coumadin (warfarin) well in advance of having any procedure done

c. Can have procedures done and there is not a need to tell the dentist about the Coumadin (warfarin)

d. Can have the dental procedure done if, when you arrive at your dental appointment, you tell the dentist you are taking Coumadin (warfarin)

12 When the need arises to take an antibiotic (to get rid of an infection) while taking Coumadin (warfarin), you need to-

a. Take half of the prescribed length of therapy, and then call the Coumadin Clinic

b. Refuse to take any new medication because you are taking Coumadin (warfarin)

c. Wait until your next Coumadin Clinic visit and then tell the pharmacist about the antibiotic

d. Call the Coumadin Clinic right away and let them know you are starting a new medication

13 Coumadin (warfarin) works-

$46.2 \%$

a. In my liver to make my blood thicker

b. In my liver to make my blood thinner

c. In my kidneys to make my blood thicker

d. In my kidneys to make my blood thinner

I4 The best time of day for me to take my Coumadin (warfarin) is-

a. At lunchtime

b. In the evening

c. In the morning before breakfast

d. Any time of day when I remember

I5 Which of the following is an effect of my Coumadin (warfarin) medication that I will most likely experience if my INR is too high?

a. A clot in the leg

b. Minor bleeding

c. Clot in the lung

d. Bleeding in the brain

I6 Which of the following drinks can decrease the effectiveness of your Coumadin (warfarin)?

a. Deans $2 \%$ low-fat milk

b. Hershey's chocolate shake

c. Tropicana orange juice

d. Ensure nutritional supplement

17 While taking Coumadin (warfarin), which of the following represents a situation when you should go to the emergency room?

a. You cough up blood

b. Your nose bleeds slightly while blowing it

c. Your gums bleed after brushing your teeth then it stops quickly

d. You have cut yourself while shaving and you control the bleeding

I8 Your neighbor brings over this great "all natural" herbal supplement she just bought from her chiropractor. She swears that this helps all her aches and pains and recommends that you take it when you ache. Your decision is to-

a. Take her advice, realizing that you could use this herbal supplement

b. Start taking the herbal supplement and tell your pharmacist at the next office visit

c. Ask your pharmacist before you take the herbal supplement whether it will interact with your medications

d. Avoid taking herbal supplements altogether because all medications interact with Coumadin (warfarin) 
Table 2 (Continued)

\begin{tabular}{|c|c|c|}
\hline Number & Question (correct answers are underlined) & $\begin{array}{l}\text { Answered } \\
\text { correctly }\end{array}$ \\
\hline 19 & $\begin{array}{l}\text { Once you have reached a stable Coumadin (warfarin) dose, a PT/INR blood test- } \\
\text { a. Should be checked once a year } \\
\text { b. Should be checked once every } 3 \text { months } \\
\text { c. Should be checked at least once every } 4 \text { weeks } \\
\text { d. Does not need to be checked once you are on a stable Coumadin (warfarin) dose }\end{array}$ & $70.8 \%$ \\
\hline 20 & $\begin{array}{l}\text { The results of your PT/INR test tells the pharmacist- } \\
\text { a. How thick or thin your blood is while taking Coumadin (warfarin) } \\
\text { b. How well your kidneys are working since taking Coumadin (warfarin) } \\
\text { c. What your average blood sugar level is since taking Coumadin (warfarin) } \\
\text { d. How much alcohol you have been drinking since taking Coumadin (warfarin) }\end{array}$ & $44.6 \%$ \\
\hline 21 & $\begin{array}{l}\text { While taking Coumadin (warfarin), you should call your Coumadin Clinic when you get- } \\
\text { a. A backache } \\
\text { b. An upset stomach } \\
\text { c. A tension headache } \\
\text { d. Diarrhea for > I day }\end{array}$ & $21.5 \%$ \\
\hline 22 & $\begin{array}{l}\text { While on Coumadin (warfarin) you need to be routinely monitored for which of the following: } \\
\text { a. PT/INR } \\
\text { b. Potassium levels } \\
\text { c. Blood glucose levels } \\
\text { d. Kidney function tests }\end{array}$ & $69.2 \%$ \\
\hline 23 & $\begin{array}{l}\text { Which of the following may have a significant effect on how well your Coumadin (warfarin) works? } \\
\text { a. Changes in your mood } \\
\text { b. Changes in sleep habits } \\
\text { c. How much water you drink } \\
\text { d. Using over-the-counter medications }\end{array}$ & $50.8 \%$ \\
\hline 24 & $\begin{array}{l}\text { While taking Coumadin (warfarin), which of the following should lead you to the emergency room? } \\
\text { a. Loss of appetite } \\
\text { b. Brown, loose stools } \\
\text { c. Urine becomes red in color } \\
\text { d. A quarter-sized bruise on your arm }\end{array}$ & $56.9 \%$ \\
\hline 25 & $\begin{array}{l}\text { Which of the following foods could affect how well your Coumadin (warfarin) works? } \\
\text { a. Celery } \\
\text { b. Carrots } \\
\text { c. Cole slaw } \\
\text { d. Green beans }\end{array}$ & $53.8 \%$ \\
\hline 26 & $\begin{array}{l}\text { You have generic and brand Coumadin (warfarin) tablets at home that are both the same dose. You should- } \\
\text { a. Take both because they work differently } \\
\text { b. Take only brand or generic, but not both } \\
\text { c. Not take either until you call the Coumadin Clinic } \\
\text { d. Alternate days by taking brand on one day and generic on the next day }\end{array}$ & $52.3 \%$ \\
\hline 27 & $\begin{array}{l}\text { Once your Coumadin (warfarin) is stopped, how long does it take to get the medication to exit your system? } \\
\text { a. } 5 \text { hours } \\
\text { b. } 5 \text { days } \\
\text { c. } 5 \text { weeks } \\
\text { d. } 5 \text { months }\end{array}$ & $26.2 \%$ \\
\hline 28 & $\begin{array}{l}\text { After starting Coumadin (warfarin), how long (in months/years) would you expect to be taking Coumadin (warfarin)? } \\
\text { a. I year } \\
\text { b. I month } \\
\text { c. It depends on each person's needs } \\
\text { d. If you start Coumadin (warfarin), you will have to be on the medication for the rest of your life }\end{array}$ & $44.6 \%$ \\
\hline 29 & $\begin{array}{l}\text { Which of the following activities are more risky while taking Coumadin (warfarin)? } \\
\text { a. Playing football, because you can hit your head } \\
\text { b. Taking a bath, because soap interacts with Coumadin (warfarin) } \\
\text { c. Playing cards because using your hands a lot will cause a blood clot } \\
\text { d. Walking a lot, because exercise is not good for you while taking Coumadin (warfarin) }\end{array}$ & $52.3 \%$ \\
\hline
\end{tabular}

Note: Underlined text indicates the correct answer.

Abbreviations: AKA, Anticoagulation Knowledge Assessment questionnaire; INR, international normalized ratio; PT, prothrombin time. 
Table 3 Spearman correlation of potential factors and TTR

\begin{tabular}{lllll}
\hline Factors & \multicolumn{2}{l}{$\boldsymbol{R}^{\#}(\boldsymbol{P}$-value $)$} & & \\
\cline { 2 - 5 } & Age & Duration & Education & Score \\
\hline Duration & $-0.045(0.722)$ & - & - & - \\
Education & $0.123(0.330)$ & $0.179(0.154)$ & - & - \\
AKA & $0.188(0.134)$ & $0.156(0.214)$ & $0.356(0.004)^{*}$ & - \\
score & & & & \\
TTR & $0.132(0.296)$ & $0.281(0.053)$ & $0.339(0.006)^{*}$ & $0.356(0.004)^{*}$ \\
\hline
\end{tabular}

Notes: ${ }^{*} R$ is the correlation coefficient; ${ }^{*} P$-value $<0.01$.

Abbreviations: AKA, Anticoagulation Knowledge Assessment questionnaire; TTR, time in therapeutic range.

there were significant associations between TTR and patients' AKA scores $(R=0.356, P=0.004)$ as well as between TTR and patients' educational levels $(R=0.339, P=0.006)$.

\section{Discussion}

This study was the first to assess warfarin knowledge level among clinical patients in mainland China. In the study population, $90.8 \%$ patients were found to have inadequate knowledge about their warfarin therapy. This number was higher compared to the result in studies conducted in Canada $(61 \%)^{14}$ and the US $(74.1 \%)^{10}$ but was lower than the study conducted in Nepal (94.1\%). ${ }^{8}$ Although direct comparison of study results is difficult because patient education methods and study methodology varied among warfarin clinics and study samples, our findings indicated poor knowledge level in our study population.

Eleven questions were answered correctly by $<50 \%$ of the patients. Five questions covered drug or diet interactions with warfarin: alcohol (Question 6), multivitamins (Question 7), pain medications (Question 1), antibiotics (Question 12), and herbals (Question 18). Question 1 addressed pain medications that can be safely used to relieve headache. Most patients indicated that they did not experience headache while on warfarin therapy, and they were not educated about this topic. Two more questions with the most-often-incorrect responses

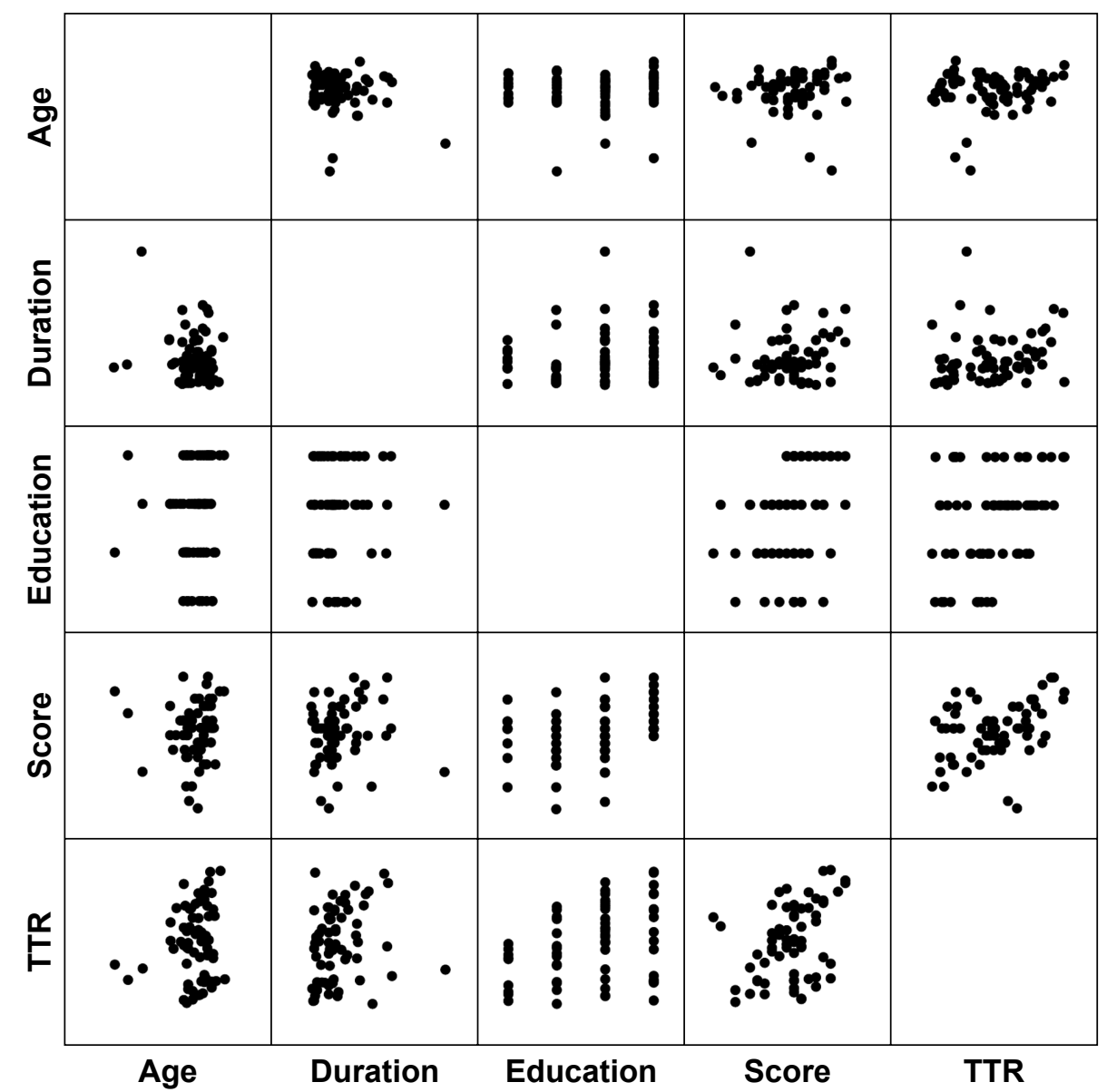

Figure I Matrix scatter plots of correlation analysis.

Notes: "Duration" indicates duration of warfarin therapy; "Education" indicates patient's education level; "Score" represents the AKA questionnaire score; TTR is presented in percentage.

Abbreviations: AKA, Anticoagulation Knowledge Assessment questionnaire; TTR, time in therapeutic range. 
covered bleeding (Question 9) and nonbleeding (Question 21) adverse reactions from warfarin therapy. Questions 15 and 20 assessed patients' understanding of the value of laboratory monitoring of INR. The question on the duration of warfarin effects, namely, the elimination time, had a correct response of only 26.2\% (Question 27). Question 28 assessed patients' understanding of the duration of their warfarin therapy. Since most patients in our study required either long-term or lifelong warfarin therapy, $35.4 \%$ patients chose the answer "taking the medication on a lifelong basis".

These frequently incorrect-response-yielding questions indicate potential areas for improvement in patient education, in addition to representing potential starting points for reeducation of current warfarin patients and future targeted education for new patients seen in the clinic aimed at the clinic's pharmacist. For example, the meaning of INR should be explained in plain, easy-to-understand language: "the INR provides some information about a person's blood's tendency to clot (which is often described as how "thin" or "thick" your blood is), and warfarin is used to raise the INR and dilute ("thin") the blood to reduce the risk of blood clot. When your INR is too high, you will most likely experience minor bleeding". Patients should be educated about how single excessive drinking causes an increase in INR and the risk of bleeding. Prior to taking over-the-counter multivitamins and "all natural" herbal supplements (agents with the perception of being safe due to their over-the-counter availability), patients should consult with their physicians and/or pharmacists whether these supplements may interact with warfarin. The most common prescription drugs that may have significant drug interactions with warfarin, such as certain antibiotics, should be reviewed with patients. Before taking these interacting medications, patients should seek advice from clinicians. Both common bleeding signs/symptoms and nonbleeding adverse effects of warfarin should be communicated to patients, along with the proper course of action to take should these events occur. It is also very important to tell patients that the duration of their warfarin therapy depends on their disease states and is individualized and that they should not stop the therapy on their own. Currently, we are conducting the reevaluation of our current standard patient education methods and instructional materials based on this analysis, and more-targeted individualized patient education will be offered to the clinic's patients by the clinic's pharmacist.

TTR is important for the safety and effectiveness of warfarin anticoagulation, and it is a way of summarizing the INR control over time. Among the 65 study patients, the mean TTR was $49.8 \% \pm 24.8 \%$, which was inadequate according to the recommended level of anticoagulant control $(>60.0 \%){ }^{15}$ This result was worse than the TTR presented by other authors. ${ }^{715-17}$ The reasons explaining our low TTR require further investigations.

The existing literature indicates mixed results when assessing the relationship between patient warfarin knowledge and INR control. A study conducted in Hong Kong found that knowledge was a determinant of anticoagulation control, and more attention should be given to the education of elderly and illiterate patients. However, only nine questions were used to test patients' knowledge of warfarin therapy, and another limitation was that only four INR results were reviewed per patient in that study. ${ }^{6}$ A study conducted in the US reported that there was no significant relationship between patient warfarin knowledge and INR control. ${ }^{10}$ Another study carried out in Malaysia reported that there was a negative correlation between patients' knowledge and age, as well as a positive correlation between patients' knowledge and education level. ${ }^{18}$ Our study found that TTR was positively related to both the patients' anticoagulation knowledge level and the patients' educational level, whereas other factors, such as age and duration of warfarin therapy, had no effect on the TTR. Based on our findings, pharmacists should spend more time or find innovative teaching techniques to educate patients with low educational levels and use the AKA as a tool to provide reeducation to current warfarin patients based on the knowledge deficits identified herein.

Our study has the following limitations: 1) the small sample size drawn from a single clinic; a large-scale and multicenter study would be necessary to generalize the study findings; and 2) aspects that could lead to INR variations, such as diets and use of herbal and/or dietary supplements, were not assessed.

\section{Conclusion}

Majority of the patients of our clinic had poor level of knowledge on warfarin. There was a significant association between the INR outcome measure and both the patients' educational level and warfarin knowledge. The frequently few correct-response-generating AKA questions represent potential areas for improvement in patient education. Pharmacists should reevaluate current educational materials and techniques to provide individualized and targeted warfarin patient education.

\section{Acknowledgment}

The authors would like to acknowledge and thank the physicians, pharmacists, and patients who participated in the study. 


\section{Disclosure}

The authors report no conflicts of interest in this work.

\section{References}

1. Zhao SJ, Zhao HW, Wang XP, et al. [Current status of warfarin therapy in Chinese patients with nonvalvular atrial fibrillation: a single center analysis]. Zhonghua Xin Xue Guan Bing Za Zhi. 2016;44(11):940-944.

2. Zhang J, Yang XA, Zhang Y, et al. Oral anticoagulant use in atrial fibrillation-associated ischemic stroke: a retrospective, multicenter survey in northwestern China. J Stroke Cerebrovasc Dis. 2017;26(1): $125-131$.

3. Ansell J, Hirsh J, Hylek E, et al. Pharmacology and management of the vitamin K antagonists: American College of Chest Physicians evidencebased clinical practice guidelines (8th edition). Chest. 2008;133(6 suppl): 160S-198S.

4. Riley RS, Rowe D, Fisher LM. Clinical utilization of the international normalized ratio (INR). J Clin Lab Anal. 2000;14(3):101-114.

5. Michaels K, Regan EN. Teaching patients INR self-management. Nursing. 2013;43(5):67-69.

6. Tang EO, Lai CS, Lee KK, Wong RS, Cheng G, Chan TY. Relationship between patients' warfarin knowledge and anticoagulation control. Ann Pharmacother. 2003;37(1):34-39.

7. van Walraven C, Jennings A, Oake N, Fergusson D, Forster AJ. Effect of study setting on anticoagulation control: a systematic review and metaregression. Chest. 2006;129(5):1155-1166.

8. Shrestha S, Sapkota B, Kumpakha A, Acharya U, Sharma R. Evaluation of patients' knowledge on warfarin in outpatient pharmacy of a tertiary care cardiac center. BMC Res Notes. 2015;8:429.

9. Briggs AL, Jackson TR, Bruce S, Shapiro NL. The development and performance validation of a tool to assess patient anticoagulation knowledge. Res Social Adm Pharm. 2005;1(1):40-59.
10. Baker JW, Pierce KL, Ryals CA. INR goal attainment and oral anticoagulation knowledge of patients enrolled in an anticoagulation clinic in a Veterans Affairs medical center. J Manag Care Pharm. 2011;17(2): $133-142$.

11. World Health Organization [webpage on the Internet]. Process of Translation and Adaptation of Instruments. 2017. Available from: http://www.who.int/substance_abuse/research_tools/translation/en/. Accessed November 10, 2017

12. Nam MH, Roh KH, Pak HN, et al. Evaluation of the Roche CoaguChek XS handheld coagulation analyzer in a cardiac outpatient clinic. Ann Clin Lab Sci. 2008;38(1):37-40.

13. Rosendaal FR, Cannegieter SC, van der Meer FJ, Briet E. A method to determine the optimal intensity of oral anticoagulant therapy. Thromb Haemost. 1993;69(3):236-239.

14. Hu A, Chow CM, Dao D, Errett L, Keith M. Factors influencing patient knowledge of warfarin therapy after mechanical heart valve replacement. J Cardiovasc Nurs. 2006;21(3):169-175; quiz 176-167.

15. Connolly SJ, Pogue J, Eikelboom J, et al; ACTIVE W Investigators. Benefit of oral anticoagulant over antiplatelet therapy in atrial fibrillation depends on the quality of international normalized ratio control achieved by centers and countries as measured by time in therapeutic range. Circulation. 2008;118(20):2029-2037.

16. de Lima Silva RG, Bertollo CM, Ferreira IG, Brant LC, Martins MAP. Assessment of oral anticoagulation control at two pharmacist-managed clinics in Brazil. Int J Clin Pharm. 2017;39(6):1157-1161.

17. Dlott JS, George RA, Huang X, et al. National assessment of warfarin anticoagulation therapy for stroke prevention in atrial fibrillation. Circulation. 2014;129(13):1407-1414.

18. Hasan SS, Shamala R, Syed IA, et al. Factors affecting warfarin-related knowledge and INR control of patients attending physician- and pharmacist-managed anticoagulation clinics. J Pharm Pract. 2011; 24(5):485-493.
Patient Preference and Adherence

\section{Publish your work in this journal}

Patient Preference and Adherence is an international, peer-reviewed, open access journal that focuses on the growing importance of patient preference and adherence throughout the therapeutic continuum. Patient satisfaction, acceptability, quality of life, compliance, persistence and their role in developing new therapeutic modalities and compounds to optimize

\section{Dovepress}

clinical outcomes for existing disease states are major areas of interest for the journal. This journal has been accepted for indexing on PubMed Central. The manuscript management system is completely online and includes a very quick and fair peer-review system, which is all easy to use. Visit http://www. dovepress.com/testimonials.php to read real quotes from published authors. 